\title{
(IN)FELICIDADE NA PUBLICIDADE E A CRENÇA DO "SER FELIZ": COLUNAS FEMININAS DE CLARICE LISPECTOR
}

\begin{abstract}
Níncia Cecília Ribas Borges Teixeira ${ }^{1}$
Resumo: Nos anos de 1950, as colunas femininas dirigiam-se às mulheres num tom intimista, como em um encontro entre amigas. A imprensa é tanto um veículo educativo quanto um meio de ocupação da esfera pública compartilhado por diversos grupos sociais. Assim, entre as décadas de 1950 e 1960, o jornal funciona como instrumento para a educação feminina e para a construção do papel social da mulher. $\mathrm{O}$ artigo tem como objetivo fazer uma análise das colunas de jornais escritas por Clarice Lispector em alguns jornais, nos quais fez uso de pseudônimos. Os conselhos que apareciam nas colunas clariceanas formavam um guia de conduta - dicas sobre etiqueta, moda, culinária, maquiagem e postura. As seções eram compostas por pequenos textos narrativos que reuniam receitas e segredos ensinavam a mulher a tornar a vida prática e faziam com que essa leitora/companheira se sentisse especial. Ao representar a figura feminina, a imprensa constrói, projeta e estabiliza identidades sociais, em processos definidos histórica e culturalmente. Assim, as representações cristalizam-se em formas textuais e se associam a outros discursos. No artigo, são mobilizados pressupostos teóricos que se ligam à imprensa feminina e representação. Palavras-Chave: Publicidade. Colunas Femininas. Clarice Lispector.
\end{abstract}

\section{(UN)HAPPINESS IN ADVERTISING AND THE BELIEF "BE HAPPY": FEMININE COLUMNS BY CLARICE LISPECTOR}

Abstract: In the 1950s, the female columns addressed to women in an intimate tone, as in a meeting between friends. The press is both an educational vehicle and a means of occupying the public sphere shared by different social groups. Thus, between the 1950 s and 1960s, the newspaper works as a tool for women's education and to build the social role of women. The article aims to make an analysis of newspaper columns written by Clarice Lispector in some newspapers, which made use of pseudonyms. The advice appeared in clariceans columns formed a conduct guide - tips on etiquette, fashion, cooking, makeup and posture. The sections were composed of small narrative texts that gather recipes and secrets taught women to make practical life and meant that this reader / partner feel special. To represent the female figure, the press builds designs and stabilizes social identities in historical and culturally defined processes. Thus, representations crystallize into textual form and are associated with other speeches. In the article, they are mobilized theoretical assumptions that bind to the women's press and representation.

Keywords: Advertising. Female columns. Clarice Lispector.

\footnotetext{
${ }^{1}$ Pós-doutora pela Universidade Federal do Rio de Janeiro (UFRJ). Doutora em Letras pela Universidade Estadual Paulista Júlio de Mesquita Filho (2005). Mestre em Letras pela Universidade Estadual de Londrina. É Professora Adjunta da Universidade Estadual do Centro-Oeste (UNICENTRO-PR). Endereço eletrônico: ninciaborgesteixeira@yahoo.com.br.
} 


\title{
Introdução
}

\begin{abstract}
O grande mal-entendido em que se assenta esse sistema de interpretação está em que se admite que é natural para o ser humano feminino fazer de si uma mulher feminina: não basta ser uma heterossexual nem mesmo uma mãe, para realizar esse ideal; a "verdadeira mulher" é um produto artificial que a civilização fabrica [...] (Simone de Beauvoir).
\end{abstract}

A Escola dos Annales promoveu o desenvolvimento de uma história das mulheres, decorrente da ênfase dada ao cotidiano, da vida privada e dos grupos marginalizados pela história positivista. De acordo com Peter Burke (2002), a História das mulheres oferece uma nova perspectiva sobre o passado, uma vez que, anteriormente, eram invisíveis, sendo subestimado seu trabalho diário, sua influência política e econômica.

A partir da década de 1980, o conceito de gênero tornou-se amplamente utilizado para caracterizar as relações entre homens e mulheres, partindo do pressuposto de que a formulação de uma história das mulheres necessita obrigatoriamente dos estudos acerca das inter-relações entre os dois sexos. A categoria gênero se reporta a uma construção social que delimita os papéis desempenhados por cada um dos sexos na sociedade. Pode ser compreendido como uma convenção social, histórica ecultural, baseada nas diferenças sexuais.

Embora a historiografia oficial omita, na maioria das vezes, a participação da mulher no processo histórico, observa-se que as mulheres não foram simplesmente um adorno no âmbito social. Nas últimas décadas, um maior número de pesquisadores voltou-se para esta discussão na tentativa de retificar esta omissão. A pesquisa analisa a representação das mulheres entre o início do século XX e início do século XXI por meio das imagens femininas presentes nos discursos da imprensa. Durante muito tempo, a mulher foi silenciada e esteve à mercê das decisões patriarcais. Até a segunda metade do século XIX, as mulheres mantiveram condições subalternas na maioria das situações do cotidiano. Sua participação social ficava restrita ao lar, aos afazeres domésticos. A presença feminina era reduzida no espaço público. Seu acesso a clubes, teatros, cafés só era permitido se estivessem acompanhadas. 
Em relação à educação formal, as oportunidades de estudos eram mínimas. Mesmo depois de 1879, quando o governo brasileiro permite às mulheres frequentarem instituições de ensino superior no país, poucas tiveram sucesso e conseguiram obter formação superior, uma vez que havia poucas escolas para moças, o que limitava ainda mais o número de mulheres que completavam o ensino secundário, essencial para a formação superior.

Norbert Elias, ao estudar a construção de identidades - dos indivíduos e das sociedades - e das representações acerca de tais construções, assevera que essas acabam propiciando modos de ação e visões de mundo, os textos expressos na Imprensa Paranaense, no começo do século $\mathrm{XX}$, estabelecem suas escritas sobre questões da memória, sobre vivências individuais, mas as quais, quando relatadas, possibilitam a (re) construção de experiências da sociedade, e, por extensão, um mapa da representação da mulher no início do século XX. Sobre esta questão Elias argumenta:

\begin{abstract}
Dessa interdependência de pessoas surge uma ordem sui generis, uma ordem mais irresistível e mais forte do que à vontade ou a razão das pessoas isoladas que a compõe. É essa ordem de impulsos e anelos humanos entrelaçados, essa ordem social, que determina o curso da mudança histórica, e que subjaz ao processo civilizador [...]A rede de interdependência entre os seres humanos é o que os liga. Elas formam o nexo da configuração, ou seja, uma estrutura de pessoas mutuamente orientadas e dependentes. Uma vez que as pessoas são mais ou menos dependentes entre si, inicialmente pela ação da natureza e mais tarde através da aprendizagem social, da educação, socialização e necessidade recíprocas socialmente geradas, elas existem, apenas como pluralidades, apenas com configurações (ELIAS, 1993, p. 194).
\end{abstract}

A expressão verbal sobre essas vivências, a partir de valores sociais e culturais de cada povo, constrói uma identidade de gênero. O significado de como ser ou agir como homens ou mulheres é dado socialmente e varia conforme as representações presentes no imaginário de cada época. Dessa forma, surgem formas que remetem a uma espécie de Pedagogia de Gênero. De acordo com Lea Archanjo (1987, p. 13): 
Representar implica uma figura e no que ela significa, ou seja, numa forma e em seu sentido. O sentido é que dá caráter simbólico à representação [...] nas representações sociais de gênero, existe a forma (figura) homem /mulher e o sentido (significação) do que é ser homem ou ser mulher. O que significa ser homem e ser mulher varia histórica e culturalmente.

A representação é um processo de construção de sentidos e não um reflexo da realidade. Ela se constitui a partir da natureza das formações discursivas em que foram concebidas, as relações de poder, os elementos da dominação e da resistência. Ao representar, são firmadas identidades. Esta dimensão da representação torna-se ainda mais evidente ao se tratar da imprensa e seu poder de influenciar as crenças, os valores, as identidades e a memória social.

Ao representar a figura feminina, a imprensa constrói, projeta e estabiliza identidades sociais, em processos definidos histórica e culturalmente. Assim, as representações cristalizam-se em formas textuais e se associam a outros discursos. Dessa forma, a imprensa é um instrumento poderoso na constituição da memória social, as representações do real veiculadas pelos meios de comunicação inscrevem-se na memória e fazem parte de nosso imaginário, na medida em que constroem as narrativas que sustentam a ideia de nação e de identidade nacional, pois adquiriram um status institucional que lhes autoriza a interpretar e produzir sentidos sobre o social, que são aceitos consensualmente pela sociedade. Ao considerarmos os códigos, discursos e narrativas sociais a que se está exposto e que estão representados nos registros da imprensa, é possível analisar as representações que serviram para construir a identidade e a memória do feminino nos/pelos periódicos que fundaram e constituíram a tradição da imprensa escrita no Brasil. Os registros da imprensa, portanto, fazem parte do elenco de narrativas e discursos que irão participar da constituição dos sujeitos e definir os contornos das relações sociais. Discurso é, portanto, prática social: estamos constantemente construindo a nós mesmos e ao mundo nas práticas discursivas em que nos envolvemos. 
Por meio da associação entre imaginário e social, as sociedades traçam identidades e estruturam representações através de símbolos, imagens, ideologias, mitos e rituais. Na construção desse imaginário, são oferecidas e modeladas as condutas esperadas, bem como os estereótipos, já que nessas relações existem articulações de poder, sendo o domínio do imaginário um importante lugar estratégico.

Para Roger Chartier (1990, p. 20), o conceito de representação deve ser entendido como um “[...] instrumento de um conhecimento mediador que faz ver um objeto ausente através da substituição por uma imagem capaz de o reconstituir em memória e de o figurar como ele é".

Os modelos transmitidos por meio dos discursos da imprensa em nossa sociedade influenciaram na formação da mulher brasileira, para Véron apud Buitoni (2009, p. 22):

[...] o discurso é uma rede de interferências. A possível análise resultará de critérios exteriores aos textos em pelos menos dois sentidos: a) a seleção dos textos; b) a finalidade da leitura a que esses textos serão submetidos.[...] A presença do ideológico no discurso não consiste em propriedades imanentes aos textos e sim em um sistema de relações entre o texto e sua produção, circulação e consumo.

A mídia, em geral, utiliza-se, no dizer de Buitoni (2009), de qualidades "quase abstratas" no que refere a presença feminina: maternidade, suavidade, doçura, para que estas permaneçam e aumentem, criando de certa forma o "mundo da mulher".

No início, as publicações femininas eram editadas em veículos destinados a um público pertencente a ambos os sexos, pois a ideia de público específico, como hoje se tem, não existia, porque a mulher não era sequer considerada. De acordo com a jornalista Dulcília Schroeder Buitoni, no livro Imprensa Feminina, as pessoas contrapõem a imprensa em geral e a imprensa feminina, no sentido de que o jornalismo de serviços seria mais para mulheres, enquanto assuntos como economia e política seriam voltados para os homens. 


\begin{abstract}
Não nos esqueçamos de que o público é uma conceituação deste século, e ligada quase sempre a várias camadas sociais. Enquanto a imprensa feminina teve em vista desde logo a mulher, a imprensa masculina, dirigida ao homem, só veio a construir-se bem depois, em função da segmentação de mercado (BUITONI, 1990, p. 8).
\end{abstract}

Maurice Duverger (1976) subdivide a imprensa especializada em imprensa de público especializado e imprensa de assunto especializado. Ele afirma que imprensa feminina é assunto especializado, assim como periódicos esportivos, literários, revistas de TV, dentre outros, de modo que o conteúdo seria responsável pela sua classificação. Essa ponderação ajuda na sua caracterização de "imprensa feminina", sem enquadrá-la, no entanto, como imprensa de assunto especializado, argumentação legitimada pelo que nos explica Buitoni:

\begin{abstract}
Imprensa de interesse geral, imprensa de público especializado, imprensa de assunto especializado, nenhuma definição é adequada ao tipo de mídia que ora analisamos. Interesse geral não seria, embora homens também sejam leitores de veículos femininos. Mulheres não constituem um público especializado; além disso, não dá para falar em especialização de assunto, porque a gama possível de matérias é muito grande (1990, p. 15).
\end{abstract}

Evelyne Sullerot apud Buitoni (2009) classifica como femininos os periódicos que se proclamam destinados à clientela feminina e que foram concebidos objetivando um público feminino. Entretanto, o ser escrita para, não implica em ser escrita por mulheres. As revistas publicadas no início do século XX, isso pesa consideravelmente, pois a maioria foi pensada e escrita, na quase totalidade, por homens, a intelectualidade brasileira do período, oriundos do nacionalismo modernista dos anos 20. De qualquer forma, isto é um reflexo da exclusão feminina da época, do afastamento das áreas da cultura e do poder; a mulher era para ser dirigida e não dirigir.

A imprensa feminina elegeu a revista como seu veículo por excelência. Revista é ilustração, é cor, jogo, prazer, é linguagem mais pessoal, é variedade: a imprensa que tem como fofo a mulher utiliza tudo isso. Quanto aos temas abordados em revistas femininas, observa-se que alguns estão 
sempre presentes como: sentimentos, conselhos de saúde, de economia doméstica, decoração, beleza. Ocorre o desprezo pelo fato atual, as matérias vinculadas por ela atingem uma certa atemporalidade, acentuando o seu desligamento com o mundo real e ativando o caráter ideológico. Todos esses elementos, Buitoni (2009), utilizam a figura da mulher como mito, ou seja, correspondente à ideologia que servem para reforçar o conceito tradicional, passando a uma espécie de representação coletiva, assim caracterizando a imprensa feminina como mítica.

Para Roland Barthes (apud BUITONI, 2009), o mito é um reflexo social que transpõe a cultura em natureza, o social em cultural, o histórico em natural. A imprensa feminina propõe modelos culturais como sendo lógicos e naturais: "O que é apenas produto das classes e de suas sequelas morais, culturais e estéticas e apresentado como evidente por si mesmo [...]tornam-se a opinião corrente" (BARTHES apud BUITONI, 2009, p. 11).

O desenvolvimento industrial trouxe consigo o aprimoramento da publicidade, ferramenta primordial na vendagem de revistas femininas, já que, ali, os anunciantes de cosméticos, moda, produtos pessoais, para a família e para a casa, encontraram sua fatia de mercado no mundo capitalista, criando assim, o hábito do consumo traduzido como ideologia.

Esse armazém sortido e agradável, que é a revista, sempre apresenta uma fruição; daí seu caráter de feminização do produto impresso. Acima de tudo, a leitura de uma revista parece mais gostosa que a de um jornal, seja pelo conteúdo ou até pela forma como é lida. Não se lêem revistas somente pela informação; muitas vezes, o ato de folheá-las já é um prazer (BUITONI, 1990, p. 18).

No Brasil, o primeiro jornal feminino foi o Espelho Diamantino, de 1827, em que se lia “dedicado às senhoras brasileiras". Nele era publicada notas sobre política, literatura, artes, teatro e moda, e era feito na cidade do Rio de Janeiro. O Correio das Modas, de 1839, carioca, também é o pioneiro das publicações para mulheres. Mas, a imprensa feminina do século XIX não se restringiu ao Rio de Janeiro e, em 1831, em Recife, foi lançado $O$ Espelho das Brasileiras, seguido de várias outras publicações do gênero, muitas vezes de 
efêmera duração. Preocupavam-se basicamente com moda e literatura. Na segunda metade do séc. XIX, a imprensa se desenvolveu e estreitou seus laços com a literatura; grandes escritores, como José de Alencar, Joaquim Manoel de Macedo e Machado de Assis tiveram suas obras publicadas nos jornais, sob a forma de folhetins, que estimulavam sonhos e fantasias de homens e mulheres, envolvidos em suas tramas amorosas.

A ilustração também passou a ser mais utilizada, graças a desenhistas como Henrique Fleiuss (Semana Ilustrada - 1860) e Ângelo Agostini (Revista Ilustrada-1876). É nesse momento que surgem “alguns periódicos audaciosos editados por mulheres", entre eles o Jornal das Senhoras, de responsabilidade de Joana Paula Manso de Noronha, que a partir de 1852, "parece ter sido um dos primeiros a contar com mulheres na redação".

Outro jornal brasileiro que merece destaque é o $A$ Família (1881-1897). Entre os temas abordados estavam o direito ao voto, o direito de serem médicas, advogadas, professoras ou de seguir a carreira teatral (que era associada à prostituição).

No fim do século XVIII, surgiu, na França, a primeira publicação que tratava sobre o desejo de emancipação da mulher, o L'Athénée des Dames, fechado em 1809 por ordem do imperador Napoleão. No Brasil, este tipo de publicação passa a existir no final do século XIX e sendo um expoente, “O Sexo Feminino" da professora mineira Francisca Senhorinha da Mota Diniz, lutava pela educação das mulheres.

Em 1862, também no Rio de Janeiro, um grupo de mulheres, com instrução secundária, fundou $O$ Belo Sexo. Mais críticas quanto ao tipo de atuação social da mulher, que, segundo elas, conduzia ao tédio e solidão de uma vida improdutiva, que as privava de uma instrução mais profunda para conduzi-las ao casamento. Em nosso país, a primeira publicação de destaque foi a Revista Feminina, veiculada de 1914 a 1936, contou com a participação de escritores famosos, como Olavo Bilac. Na década de 40, surge a Página Feminina, uma publicação semanal vespertina, com colunas sobre beleza, moda e culinária.

June E. Hahner (1981), que estudou essas publicações da imprensa feminina, refere-se ao pouco destaque que elas têm merecido por parte de 
estudiosos da imprensa e dos movimentos feministas. Lembra que essas mulheres, através de seus jornais, procuravam despertar as demais para o desenvolvimento de um potencial sufocado e desconhecido. Acreditavam na educação como instrumento mais eficaz para libertar a mulher da opressão que vinha sofrendo há séculos. Algumas tiveram ideias avançadas para a época.

Coube à imprensa feminina divulgar as novas ideias sobre o elemento feminino, que, em geral, referendava o domínio social e familiar do homem. A imagem da "nova" mulher divulgada por essa imprensa foi naturalizada e, inclusive, reproduzida por aquelas que participaram direta ou indiretamente da escrita desses periódicos, em especial, nos jornais femininos. Buitoni (2009) assevera que o novo, o moderno é perseguido a qualquer custo pela imprensa feminina, mas não o novo notícia, é um novo ideológico que possui caráter ambíguo: [...] a busca inquieta na arte de vestir, de julgar, reveste-se de um conservantismo moral. As mulheres sabem que a estabilidade de uma sociedade ou sua continuidade repousa na mão das mães. Elas inspiram uma imprensa que devia, para lhes agradar, ser a à sua imagem (BUITONI, 2009, p. 25).

Entretanto, há que se registrar a existência de jornais para mulheres que se revoltaram com esta posição e tornaram-se feministas em suas causas, como aconteceu com o $A$ Família, fundado em 1888, no Rio de Janeiro, por Josefina Álvares de Azevedo - onde ela defendeu o sufragismo e reivindicou a igualdade prometida pela República recém-implantada. Josefina Álvares de Azevedo, por exemplo, foi das mais vigorosas das vozes femininas surgidas nas décadas de 1880-1890. Rebelou-se contra a dominação do homem. As ideias de Josefina de Azevedo avançaram na defesa da lei do divórcio, que permitiria a dissolução legal de casamentos já desfeitos por acordos mútuos. Essas publicações críticas e conscientizadas da dominação masculina, porém, não foram as dominantes no gênero. À medida que se caminhava para o final do século, elas rareavam e eram substituídas por outras, mais amenas, com títulos com nomes de flores, pedras preciosas, animais graciosos, todos metáforas da figura feminina: A Camélia, A Violeta, O Lírio, A Crisálida, A Borboleta, O BeijaFlor, A Esmeralda, A Grinalda, O Leque, O Espelho, Primavera. 
Além dos jornais, as revistas também passaram a ter maior número de leitores, aparecendo novas publicações. Já havia público para revistas mundanas, ricas e luxuosas que, favorecidas pelo desenvolvimento das artes gráficas, apresentavam belas ilustrações e até fotografias. Essas revistas já voltavam sua atenção para o público feminino, incluindo matérias ou seções supostamente de interesse feminino. Assim faziam a Revista da Semana (Rio de Janeiro-1901), que tinha uma seção intitulada Cartas de Mulher; Fon-Fon (Rio de Janeiro -1907) e Cigarra (São Paulo-1914), que embora não fossem concebidas como revistas especificamente para público feminino, traziam informações para este público. As mulheres ganhavam espaço nas matérias e propagandas das revistas de maior circulação, mas não tinham, então, uma publicação que a elas se dedicasse exclusivamente. Esse espaço veio a ser preenchido pela Revista Feminina.

Esses periódicos, na sua maioria, tiveram vida curta. Em geral, suas edições, ao lado de assuntos sobre moda, culinária e educação dos filhos, publicavam artigos mais polêmicos, onde se discutia a condição da mulher e chegavam até a reivindicar direitos e oportunidades iguais para ambos os sexos. Entre as escritoras que mereceram presença nesses periódicos estão: Júlia Lopes de Almeida, Narcisa Amália, Amália Franco, Inês Sabino, Carmem Dolores, Corina Coaracy e Maria Amélia de Queirós.

No início do século XX, o crescimento da urbanização e da industrialização nos grandes centros traz a mulher para o espaço público das ruas, dos acontecimentos sociais nos teatros, cafés e ao mundo do trabalho. Neste momento, surgem em maior quantidade, textos sobre a mulher e também escritos por elas. O movimento pelos direitos da mulher começa então a se fortalecer no Brasil, principalmente entre as elites urbanas. As reivindicações dessas mulheres, ligadas a um estrato social mais privilegiado, voltavam principalmente para os debates que diziam respeito aos direitos de igualdade perante os homens quanto à profissionalização e ao direito de voto.

As práticas discursivas produzidas pela imprensa são formas simbólicas, que veiculam noções existentes na sociedade, reproduzindo crenças, valores e identidades sociais, retratando alterações históricas, e contribuindo para a perpetuação ou transformação das relações sociais. Parto 
do pressuposto de que os contextos sociais são constitutivos da produção das formas simbólicas, e dos modos pelos quais essas formas são recebidas e entendidas, contribuindo também para as maneiras pelo qual elas serão interpretadas, recebidas e valorizadas. As sociedades constroem bens simbólicos, que compõem o imaginário e formam um conjunto de representações sociais.

A partir do nascimento, ocorre uma série de ideias acerca da feminilidade e da masculinidade, por meio da transmissão/incorporação de determinados "valores femininos e masculinos" ratificados pelas instituições: Família, Igreja, Mídia. Há a construção do senso comum que parte do pressuposto de que a sociedade compartilha de um consenso cultural. Ele é uma forma simbólica, munido de valores e significados sobre homens e mulheres existentes na sociedade. Existe, também, o emprego de um discurso normatizante, por meio de representações coletivas e classificatórias para que seja entendido por um maior número de pessoas.

O final do século XIX foi marcado no Brasil pela expansão da imprensa, graças aos avanços tecnológicos propiciados pela época. No entanto, os periódicos dependiam de colaboradores literários e financeiros para a sua sobrevivência, além de um número considerável de leitores que na época, eram as mulheres, a quem estes eram destinados, principalmente no espaço intitulado folhetim, no qual eram publicadas variedades e assuntos corriqueiros ditados pela sociedade burguesa que se encaixavam ao perfil feminino. Apesar de que nesse período apenas $20 \%$ das mulheres sabiam ler e escrever, contra $29 \%$ dos homens alfabetizados, elas eram as leitoras da época

$\mathrm{O}$ século $\mathrm{XX}$ foi um período marcado por inúmeras tensões, mas também foi um século de conquistas e de grande visibilidade, em especial para as mulheres.

No Brasil, a situação das mulheres era semelhante ao que ocorria no restante do mundo. No início, apenas a elite brasileira - econômica e cultural - discutia ideias feministas; depois, com a inserção de imigrantes nos espaços sociais, entre as décadas de 1920 a 1940, doutrinas e ideias libertárias estiveram acessíveis à camada das trabalhadoras. A imprensa feminina constitui-se num espaço privilegiado para que se possa desvendar esse universo. Os periódicos 
antigos destinados ao sexo feminino ajudam a revelar não só o lugar que lhe era reservado naquela sociedade, mas, principalmente, o grau de conscientização das mulheres cultas quanto ao papel que ocupavam na mesma. Propomos, então, estudar mulheres da classe dominante, por isso precisamos relativizar e redimensionar seu papel em vista de uma ideia preconceituosa a elas associada - submissa, dócil, rebelde - tão amplamente divulgada.

\section{Clarice Lispector: máscaras e consumo}

Mas já que se há de escrever, que ao menos não se esmaguem com palavras as entrelinhas (Clarice Lispector).

A carreira jornalística de Clarice Lispector começa com um convite de Rubem Braga para escrever uma coluna feminina no jornal Comício. O semanário funcionava na Cinelândia, na rua Álvaro Alvim e era impresso na gráfica do Última Hora de Samuel Wainer. De vida curta, o tablóide circulou de 15 de maio a 17 de outubro de 1952. Comício tinha Millôr Fernandes responsável pelo humor na página central; Paulo Mendes Campos escrevia a seção "Por esse mundo de Deus" e Rubem Braga assinava "Os dias do presidido", uma espécie de resposta irônica "O dia do presidente" publicada no Última Hora de Samuel Wainer. Surgia ali a faceta, ainda pouco conhecida, de uma das escritoras mais importantes da literatura brasileira, Clarice Lispector. O ofício de romancista passa a dividir lugar com a função paralela de jornalista, ao buscar o trabalho na imprensa para completar o orçamento e também porque gostava de atuar, Clarice Lispector se apropriava dos vários gêneros dos veículos impressos de comunicação, apreendendo a técnica e a linguagem, para, em seguida, apresentar uma concepção muito própria de fazer jornalismo. Ao delinear a trajetória da escritora nos jornais e revistas do Rio de Janeiro, sobressaem ainda informações importantes para o resgate da memória do jornalismo, pois Clarice Lispector foi uma das primeiras mulheres a atuar no jornalismo brasileiro e na imprensa feminina nacional.

Além do Comício (1952), atuando com o pseudônimo Teresa Quadros, escreve no Correio Feminino, assinando como Helen Palmer e está presente, 
também, escrevendo as colunas “Entre Mulheres”, no jornal e a coluna “Só para Mulheres", como ghost writer da modelo e manequim Ilka Soares, no jornal Diário da Noite (1943). A investigação da construção dos corpos materiais no jornal, feitas pela escritora, aponta para a origem de um perfil feminino que ocupará as páginas da sua ficção.

Clarice Lispector, no papel de jornalista, criou pseudônimos Tereza Quadros, Helen Palmer e Ilka Soares, analisando as peculiaridades temáticas de cada uma e a maneira com a qual Clarice se dirigia ao público feminino da época. O estudo da imprensa feminina do Brasil, desenvolvido por Dulcília Schroeder Buitoni, serve como aparato teórico ao entendimento do modo em que Clarice Lispector se portava como jornalista feminina nas décadas de 50 e 60 , período no qual o auge da revolução feminista ainda não tinha acontecido.

Edma Cristina Alencar de Góis assevera que:

Um dos motivos que torna mais instigante a pesquisa é o quase uníssono sobre a obra de Clarice Lispector no jornal para e sobre mulheres. A produção jornalística é sempre tida como inferior à literária. Quando essa produção está no terreno da imprensa feminina, então, é praticamente esquecida, colocada de lado, encarada como de pouco valor (GÓIS, 2007, p. 12).

Escritora, jornalista, tradutora, esposa, mãe. A vida de Clarice Lispector é permeada de lirismo e singelezas; a palavra foi sua cúmplice por toda a vida. A ideia inicial de Clarice não era ser romancista, tampouco jornalista. Ela formou-se em Direito na Faculdade Nacional de Direito da Universidade do Brasil, no Rio de Janeiro. Foi durante seu curso que a moça percebeu que tinha aptidões para a escrita e começou a fazer trabalhos em jornais e revistas. Sua primeira entrevista publicada e também sua estreia como ficcionista foram em 1940, na Vamos ler! e na revista Pan, respectivamente. O mais interessante é que, apesar de ter escrito alguns textos para jornais durante sua faculdade, assinando como Clarice Lispector mesmo, seu lado jornalístico mais interessante diz respeito às colunas femininas que escrevia utilizando pseudônimos. 
Apesar das posições distintas da Clarice jornalista e da Clarice romancista, pode-se encontrar muito de uma na outra; é como se as duas funções complementassem o seu universo temático. Muito da feminilidade e da polidez, características sempre bastante sugeridas nas dicas das suas colunas, são presentes nas composições das personagens de seus romances; muitas das sutilezas e detalhes comuns em sua ficção também podem ser visíveis em seus escritos jornalísticos.

Além de Tereza Quadros, codinome utilizado em “O Comício”, Clarice também escreveu para os jornais Correio da Manhã, como Helen Palmer, e para o Diário da Noite, como a ghost writer da atriz e manequim Ilka Soares. Mas por que Clarice não se identificava em seus escritos jornalísticos? Seria por que suas colunas não condiziam com sua posição como escritora renomada e à frente de seu tempo ou com a posição de esposa de um representante diplomático?

No Comício, Clarice, sob o pseudônimo de Tereza Quadros, publicou uma coluna intitulada "Entre Mulheres". Utilizava uma linguagem simples, acessível a todos os tipos de leitoras, assim se aproximou dos anseios femininos, fazendo com que as mulheres que liam suas colunas se sentissem como suas amigas íntimas. De acordo com Aparecida Maria Nunes,

Sob o pseudônimo de Tereza Quadros, Clarice Lispector publicará nesta sua coluna feminina alguns rudimentos de crônica em páginas onde se misturam conselhos de etiqueta, moda, culinária, maquiagem, postura e tudo o mais que cerca o universo da mulher, mãe e esposa (NUNES, 2006, p. 2).

Pode-se dizer que Tereza Quadros foi um primeiro passo na carreira de colunista de Clarice Lispector. Suas crônicas jornalísticas não ficaram atadas aos temas relacionados ao lar e à família, por muitas vezes, ultrapassa limiares do trivial e corriqueiro.

O que se comprova é que a ficcionista incluiu, no contato semanal com as leitoras de Comício, um bocado dos seus gostos literários. Porque, além de falar de roupas e de outros assuntos considerados fúteis, Tereza Quadros 
também reproduzia textos e opiniões de autores que, esses sim, sua criadora precisava ter "experimentado" (Encarte da edição especial dos Cadernos de Literatura Brasileira, 2004, p. 6).

A coluna "Entre Mulheres" durou apenas quatro meses - de maio a setembro de 1952 - mas foi tempo suficiente para Clarice se consagrar como um dos grandes nomes da imprensa feminina da época.

Clarice Lispector escreveu para 17 das 23 edições do breve Comício, que circulou por apenas seis meses, tendo faltado com o texto em apenas uma edição. A autora sempre equilibrava os textos sobre assuntos estritamente femininos com trechos ficcionais de sua autoria e de autores por ela admirados. Nem por isso a junção parecia inoportuna. Ao contrário, a coluna parecia ter unidade, apresentando várias facetas para a leitora. Assim, “Entre Mulheres" constitui-se como um mosaico clariceano, em que o aproveitamento ou a reelaboração de textos eram práticas comuns (GÓIS, 2007, p. 58).

A partir de agosto de 1959, Clarice passa a assinar a segunda coluna feminina, “Feira de Utilidades”, presente no jornal Correio da Manhã. No jornal, deixa seu codinome Tereza Quadros de lado e encarna outra personagem, dessa vez o nome escolhido era Helen Palmer. Assim como o nome da colunista mudou, alguns temas também passaram a ser tratados de forma diferente. Muitos consideram que Helen era muito menos sofisticada do que Tereza Quadros, portanto, percebe-se que Clarice Lispector realmente era uma rainha nos jogos do disfarce.

A colaboração tinha o patrocínio da indústria de cosméticos Pond's, que propusera a coluna, determinando inclusive a sua forma, com o objetivo de passar à leitora mensagens publicitárias "subliminares". Sem mencionar a marca, a seção deveria fazer com que o seu público associasse os conselhos de beleza ali apresentados aos produtos que a empresa anunciaria (Encarte da edição especial dos Cadernos de Literatura Brasileira, 2004, p. 7). 
Como Helen Palmer, Clarice exerceu uma função que podemos presenciar explicitamente em nossa imprensa feminina atual: ela ajudou a fortalecer os padrões de beleza da época, incentivando o uso de cremes, maquiagens e artifícios para retardar o envelhecimento:

Os temas corriqueiros são dicas de tratamento para todos os tipos de pele, uso de vitaminas, cuidados com os cabelos e emagrecimento da silhueta. Ela deixa claro que a imagem da mulher deve estar em perfeita sintonia com a beleza e dá conselhos de como fazer isso [...] (GÓIS, 2007, p. 88).

A mulher da década de 60 não era muito diferente da atual; a velhice sempre foi um fantasma a ser combatido.

[...] tais idéias tinham também por meta levar a mulher com mais idade, aquela com mais de trinta anos, a nutrir sentimentos de insegurança por envelhecer. Para impor um produto, a indústria dos cosméticos, juntamente com a mídia, cria padrões de beleza e consagra a mulher jovem (NUNES, 2006, p. 9).

A coluna no jornal Correio da Manhã durou até fevereiro de 1961, quando seu trabalho como Helen Palmer chegou ao fim, Clarice que escrevia paralelamente a coluna "Feira de Utilidades", no jornal Diário da Noite, assume a função de ghost writer da modelo e atriz Ilka Soares, uma das moças mais bonitas e famosas da época.

A celebridade e a escritora começaram um "trabalho de equipe", reunindo-se para acertar detalhes de "Só para Mulheres" (esse era o nome da seção); conversavam em especial sobre moda, Clarice Lispector ouvindo Ilka Soares, como se fosse uma repórter, ou observando a atriz, com olhos ficcionistas, para compor sua personagem (Encarte da edição especial dos Cadernos de Literatura Brasileira, p. 7, 2004).

Nas páginas de “Só para Mulheres", Ilka Soares, ou melhor, Clarice Lispector, “[...] incorporando o universo das passarelas e o glamour das estrelas, conversa diariamente com sua leitora[...]. A colunista, num discurso de 
intimidade, compartilha os seus segredos com o público que a lê" (NUNES, p. 10, 2006). Como Ilka, Clarice porta-se de forma distinta, agora ela não é só a amiga experiente que entende a leitora e oferece conselhos sentimentais e sociais; Ilka Soares é a mulher de sucesso, realizada na vida, que compartilha dicas e tendências do momento, mas que se posiciona, não num patamar igual ao da leitora, mas em uma posição superior.

Segundo Aparecida Maria Nunes, na coletânea de crônicas realizada sob sua organização, Correio Feminino, Clarice Lispector escreveu de segunda a sábado, de abril de 1960 a março de 1961, 291 colunas de página inteira, sendo também responsável pela diagramação de suas páginas. Ela não pensava apenas em relação a sua escrita, necessitava, também, visualizar como sua página ficaria composta. Recortes de revistas européias e desenhos bastante coloridos eram utilizados para compor a editoração do "Só para mulheres". Se analisarmos a imprensa feminina atual, por exemplo, revistas como Cláudia, Marie Claire e Nova, perceberemos que a diagramação bastante delicada e colorida continua fazendo parte das editorias.

Uma das grandes polêmicas em relação aos textos femininos que Clarice Lispector escreveu diz respeito a suas classificações. Alguns estudiosos afirmam que os textos são colunas, outros acreditam que eles podem ser considerados crônicas jornalísticas. Edma Cristina Alencar de Góis preferiu classificar os textos jornalísticos de Clarice como colunas. Em sua essência, a coluna é o entrecruzamento de várias expressões noticiosas.

A coluna como gênero possui pontos de intersecção com a crônica e o comentário, mas também divergências que a tornam autônoma. A crônica, por exemplo, ainda que aproximada da função poética e formulando um pacto literário, apega-se a um fato cotidiano como enredo. Ela também pode migrar para o campo literário. Já a coluna funciona como um conjunto de pequenas ou médias notas sobre assuntos diversos (GÓIS, 2007, p. 25).

José Marques de Melo nos dá outra definição de coluna:

A coluna é a seção especializada de jornal e revista, publicada com regularidade, geralmente assinada, e 
redigida em estilo mais livre e pessoal do que o noticiário comum. Compõe-se de notas, sueltos, crônicas, artigos ou textos-legendas, podendo adotar, lado a lado, várias dessas formas (MELO apud GÓIS, 2007, p. 25)

De acordo com Davi Jr Arrigucci (1987), a crônica está estritamente ligada à noção de tempo. Quando apenas jornalística, ela passa pelo mesmo processo dos jornais: perde sua atualidade diariamente e é esquecida facilmente, sendo substituída por outra e mais outras. O caráter literário das crônicas jornalísticas só é adquirido na medida em que elas ultrapassam as barreiras do tempo e do espaço, que sobrevivem às tantas outras que se apresentam posteriormente e continuam com o ar da novidade e da contemporaneidade de suas ideias, qualidades que se configuram na literariedade e que colocam-nas no rol das ditas obras literárias.

[...] Agora se trata simplesmente de um relato ou comentário de fatos corriqueiros do dia-a-dia, dos faits divers, fatos da atualidade que alimentam o noticiário dos jornais desde que estes se tornaram instrumentos de informação de grande tiragem, no século passado. A crônica virou uma seção do jornal ou da revista. Para que se possa compreendê-la adequadamente, em seu modo de ser e significação, deve ser pensada, sem dúvida, em relação com a imprensa, a que esteve sempre vinculada com sua produção (ARRIGUCCI, 1987, p. 52).

Como jornalista Clarice utilizou-se de pseudônimos para assinar as colunas, não se pode colocar que os conselhos veiculados nas colunas reflitam a opinião pessoal de Clarice. Assim, não se coloca aqui a faceta escritora de Clarice Lispector como um modelo com o qual Clarice Lispector colunista possa ser comparada, posto que, a jornalista foi uma das primeiras repórteres brasileiras ao inserir-se em um ambiente predominantemente masculino e sua ficção assumiu diversos aspectos de vanguarda. Ainda que os aspectos particulares de Clarice não possam ser tomados aqui como comparativos, a escrita clariceana guarda algumas aproximações com o imaginário feminino. Em sua obra Clarice retratou os limites convencionados para a existência feminina. 


\section{Colunas femininas e pílulas de felicidade}

Cuidar de sua beleza, arranjar-se é uma espécie de trabalho que lhe permite apropriar-se de sua pessoa como se apropria do lar pelo seu trabalho caseiro; seu eu parecelhe, então, escolhido e recriado por si mesma. Os costumes incitam-na a alienar-se assim em sua imagem (BEAUVOIR, 1967, p. 296).

Uma das formas mais comuns e mais intensas pela qual somos interpelados pela cultura de consumo é a publicidade que deixa transparecer os signos dos quais se apropria na vida cotidiana e, ao mesmo tempo, funciona como um dos agentes catalisadores do processo de construção deste conjunto auto-referenciado de significantes do qual se trata. Assim, a publicidade se alimenta e é alimentada pela cultura de consumo de forma que, ao analisar uma peça publicitária, situando-a em um contexto de produção e recepção, é possível ler (por meio dos signos) e compreender muito a respeito da sociedade, dos valores e da cultura onde aquela mensagem foi forjada. É por este desvão que o presente trabalho pretende enxergar o ideal de felicidade na escrita das colunas de Clarice Lispector.

Nas colunas escritas por Clarice é possível analisar a constituição das subjetividades das leitoras a partir da exposição de bens mercadológicos em um espaço voltado exclusivamente para o público feminino e que enseja, por meio de formas de sedução da leitora, encaminhar dicas para a felicidade. As colunas de Lispector trazem assuntos ditos de "interesse da mulher" estabelecendo um discurso sobre as referências socialmente condicionadas e condicionantes da natureza dos femininos e masculinos possíveis. Dessa forma, pode-se considerar páginas inscritas naquilo que Buitoni nomina como Imprensa Feminina.

Nos anos 1950, com o pós-guerra a existência de uma indústria produtora a todo vapor pedia um mercado consumidor que desse conta da demanda. Um boom comercial acabou gerando um boom publicitário: propagandas para estimular o consumo. No Brasil, a televisão ainda não havia se popularizado, logo o meio mais utilizado para a propaganda eram as revistas. 
Extremamente popular no Brasil, as revistas eram o meio de comunicação mais consumido. As revistas femininas davam dicas e conselhos para as mulheres suprirem as expectativas de serem boas esposas, mães e donas-de-casa, fazendo todo o serviço que lhes era destinado com cuidado, apreço, carinho, capricho e principalmente dedicação e disposição, pois também era esperado que elas nunca cansassem desses serviços e sempre estivessem dispostas e bem cuidadas.

Clarice Lispector lançou mão em suas colunas, nos jornais, de temas referentes à mentalidade do público feminino da época. Dessa forma, ela adquire a confiança e a cumplicidade de suas leitoras, que a viam como uma amiga próxima. Sua escrita é em tom de conversa sobre coisas simples, revela segredos e apresenta novidades do universo das mulheres.

\begin{abstract}
A imprensa feminina circunscreveu assim um lugar de iniciação para que o conhecimento seja transmitido. Essa informação é mantida intencionalmente escondida e existe uma espécie de contrato que se firma de modo subjacente entre a colunista e a leitora para não revelar aquilo que the vai ser confiado (NUNES, 2008, p. 147).
\end{abstract}

Os textos "Aparência: tudo tem jeito", escrito por Ilka Soares, no Diário da Noite (10 de fevereiro de 1961); e "Os espelhos da alma”, escrito por Helen Palmer, no Correio da Manhã (2 de junho de 1960 têm uma temática em comum: a busca por uma aparência atraente e por uma melhor autoestima, que levaria a mulher a ser mais feliz. A mulher moderna a deveria estar bem sintonizada com as tendências de beleza, entretanto, mais do que se arrumar para se sentir bem, ela deveria estar linda para impressionar o seu amado e conseguir mantê-lo ao seu lado sem olhar para outras.

O casamento ideal nos anos 1950 era baseado no afeto, uma vez que casamentos arranjados já estavam fora de moda, na capacidade de sustento e principalmente nas qualidades femininas. A esposa deveria ser afável, dedicada às tarefas domésticas, à educação dos filhos, carinhosa e 
compreensiva com o marido, mostrar-se sempre disposta, a construir a felicidade da família.

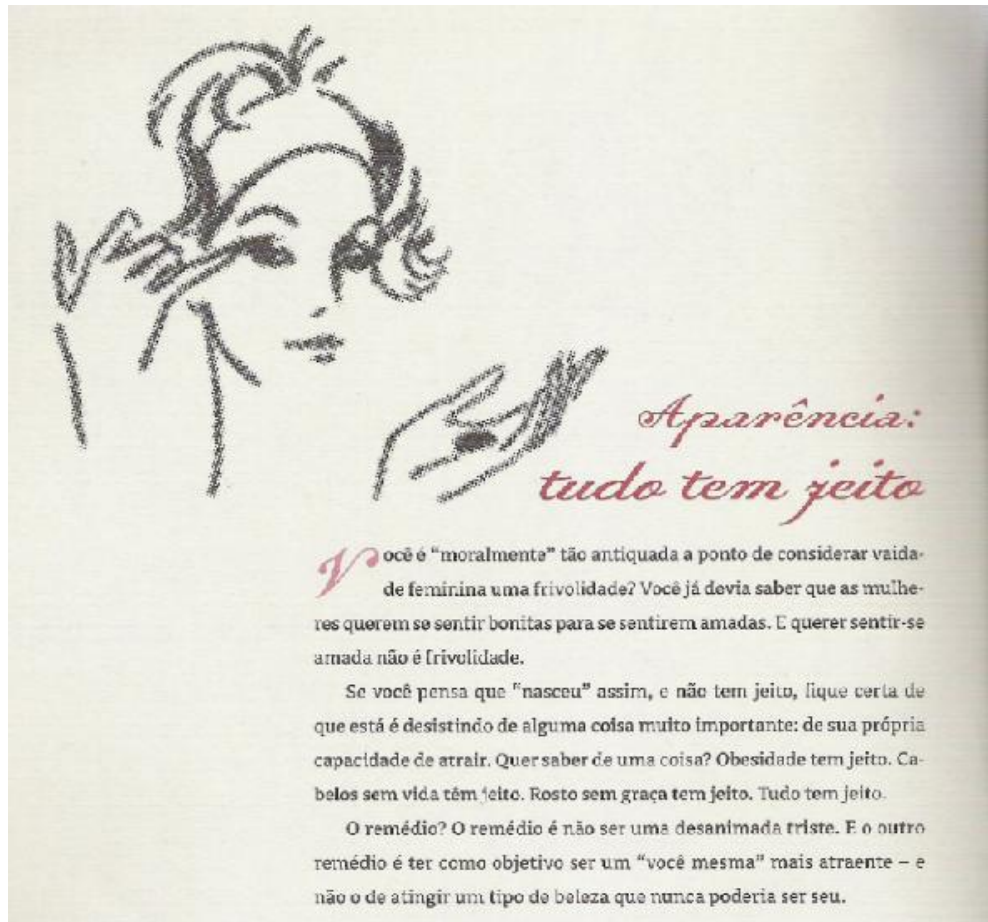

Figura 1-Livro “Só para mulheres”, 2008, p. 6

O texto "Aparência: tudo tem jeito" foi escrito por Clarice sob o pseudônimo de Ilka Soares, considerada símbolo de feminilidade, fama e beleza, por consequência ícone da mulher feliz e realizada. Ela conversa com a leitora como quem conhecesse, de fato, o mundo das passarelas. Lispector valese de fontes como a Vogue e Elle, internacionais. O texto tem como finalidade resolver os problemas da mulher moderna. A diagramação privilegia as fotografias de moda, em proporções até exageradas para atrair a atenção da leitora. Fios de variados tipos e espessuras delimitam imagens e notas. Os desenhos, de traços leves, realçam as narrativas que ilustram, destacando o lado otimista da vida.

No texto analisado, é apresentado, logo no início, um tom questionador ao se dirigir à leitora perguntando se ela é "moralmente 
antiquada" por considerar a vaidade uma frivolidade, dessa forma, observa-se uma ideologia que apresenta a mulher como modelo de beleza e perfeição, e por essa razão é invejada. Em suas colunas, Clarice dirigia-se a mães, donas de casa e jovens senhoras que, nos anos 50 , já intercalavam as atividades do lar com o mundo do trabalho.

A vaidade da mulher, cultivada como atrativo feminino, não poderia morrer após o casamento, pois cabia a mulher manter o marido interessado por ela e longe de infidelidades - consideradas normais ao espírito masculino. $\mathrm{O}$ casamento é, pois um objetivo para a mulher e a maternidade um fim em si para a leitora das colunas femininas, desprovida de qualquer alternativa. Casamento e maternidade aparecem nas linhas das colunas como um destino irrevogável. Eis que surge, então, uma infinidade de produtos de beleza, prometendo agilidade e eficiência. Maquiagens, sabonetes, tônicos, loções, produtos para o cabelo, uma gama de cosméticos que ajudavam a mulher a se cuidar sem perder tempo.

A grande verdade é que o mercado com público alvo feminino na época respondia a uma necessidade das mulheres: a economia de tempo. Com todas as funções femininas, começou a difundir-se a imagem da mulher menos devotada e mais marcada pelo espírito de sedução, de emancipação aos costumes tradicionais e pela felicidade consumista.

Ao registrar que tudo relacionado à beleza pode ser construído e conquistado, pois depende da força de vontade de cada um, Lispector propicia uma valorização na autoestima da leitora e confere uma certa esperança de mudança a mulheres que, muitas vezes, viviam de forma submissa, passiva e sem perspectivas de mudança. A intenção é mostrar à leitora que ela pode não ser a pessoa mais linda do mundo, mas que, cada pessoa tem uma beleza peculiar e particular e a sedução advém da confiança depositada em si mesma.

A colunista, então, ensina sua aluna aplicada a distinguir beleza de sedução. Reforça que, para ser amada, a mulher não precisa ser bela. Assim, em tom protetor, consola aquela leitora que se sente rejeitada pela vida por não possuir dotes de beleza. Haverá um caminho: o da sedução. Mas o que é seduzir? Um processo de difícil entendimento. 

bem, mas que tem lá seus efeitos (NUNES, 2007, p. 287).

Nota-se que a coluna configura-se como uma verdadeira aula de sedução, e tem como objetivo alertar a leitora que ela própria deve se esforçar por entender e praticar. Não existe uma fórmula exata de sedução que a mulher possa aplicar com resultados imediatos, ou seja, ela precisará descobrir por si só.

Lispector (como Ilka) perpetua o discurso, já tão presente na sociedade, de que as mulheres precisam ser bonitas e bem cuidadas para serem amadas e felizes, porém, mesmo ao utilizar o senso comum, Clarice mostra vestígios de suas sutilezas de escritora, ao registrar que a mulher só é bonita quando deixa a tristeza de lado e decide não imitar padrões alheios. Assim, por meio do desvão da escrita dá a entender que a beleza não é tudo e que a alma da pessoa vale muito mais que o seu exterior.

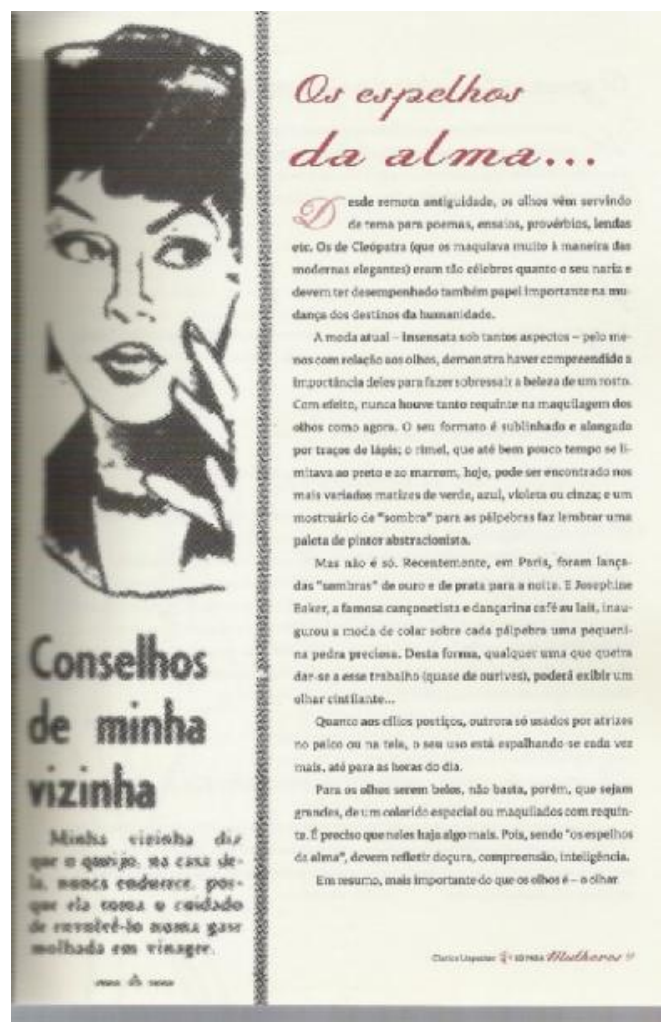

Figura 2 - Livro “Só para mulheres", 2008, p. 12 
O texto Os espelhos da alma foi escrito por Clarice na época em que ela trabalhava no Correio da Manhã com o pseudônimo de Helen Palmer. O Correio da Manhã se destaca na história da imprensa brasileira por ter se posicionado sempre contra as oligarquias e por dar ênfase à informação em detrimento da opinião. Por fazer oposição aos governos corruptos, o jornal, que foi publicado até 1974, teve sua circulação interrompida em várias ocasiões.

A coluna "Feira de utilidades" era patrocinada pela indústria de cosméticos Pond's, logo, os temas mais recorrentes eram voltados à beleza. Clarice não fazia uma propaganda explícita para sua patrocinadora, mas pautava o que escreveria de acordo com o que fosse mais conveniente à empresa, por exemplo, se a Pond's lançasse alguma maquiagem para os olhos, ela provavelmente escreveria algo sobre o valor do olhar.

\footnotetext{
Com os novos papéis desempenhados pela mulher na sociedade, agora às voltas com a indústria do consumo e, conseqüentemente, com a indústria da beleza, a colunista, mediante uma leitura dos textos publicados, teme que a leitora adote comportamentos que considera masculinizados, sobretudo os que se sobressaem com os gestos, as palavras e as atitudes: palavreado grosseiro e liberdade exagerada de linguagem ou de maneiras. A feminilidade, explica, denota alegria e delicadeza (NUNES, 2007, p. 281)
}

Como Helen Palmer, Clarice compõe sua coluna exaltando a figura da mulher que é boa esposa e boa mãe. Vaidade que deveria ser mantida também após o casamento, não de forma exagerada ao ponto de enciumar o marido, mas somente o suficiente para manter sua atenção presa na esposa, como aponta Carla Bassanezi: “Embelezar-se para o marido era uma obrigação da boa esposa e fazia parte da receita para manter o casamento: a caça já foi feita, é preciso tê-la presa. Um homem que tem uma esposa atraente em casa esquece a mulher que admirou na rua". (BASSANEZI, 2004, p. 628). Então, a indústria cosmética se desenvolve, e a quantidade de itens "essenciais" a beleza feminina é disseminada: a maquiagem, os tônicos faciais, sabonetes, esmaltes, xampus. Com o discurso da facilidade e economia de tempo, os cosméticos são vendidos como meios capazes de conservar a juventude e a vida feliz do casal. 
Em forma de "conversa mole", expressão empregada pela escritora, a colunista dá a conhecer sobre comportamentos e posturas que tornem a leitora feminina e moderna, ou seja, adaptada às exigências da nova década que se avizinha: os anos 1960

No texto Os espelhos da alma, a colunista escreve sobre a importância de ter belos olhos e de como uma maquiagem bem feita pode ajudar nessa tarefa; ela comenta sobre as tendências de maquiagens da época e sobre como olhos bem pintados têm um grande valor na aparência feminina através dos tempos, prova disso é Cleópatra.

Em suas colunas, Clarice escreve para cultuar a beleza tão almejada na sociedade de consumo, porém, ao mesmo tempo que alerta que olhos bem pintados chamam a atenção, afirma que o mais importante é o brilho do olhar. A temática "sedução e feminilidade" será a tônica das colunas escritas por Helen Palmer. Receitas de toda ordem, sob esse paradigma, serão divulgadas. Reproduz, dessa foram, uma fórmula que as revistas femininas incansavelmente divulgam, na qual o homem é referência única para a existência da mulher.

Tanto no texto Aparência: tudo tem jeito como em Os espelhos da alma, a escritora se utiliza de argumentos bastante paradoxais: fala sobre a importância da beleza e de sempre estar bem arrumada, mas ressalta que para ser bonita por dentro e por fora é necessário ter algo a mais, é necessário ter uma alma pura e um espírito alegre. Clarice usa das suas artimanhas de dizer e desdizer, de mostrar e de deixar ficar subentendido. O que parece ser fútil e superficial, na realidade, tem uma profundidade não vista à primeira vista.

\section{E a ocasião faz o ladrão? Conclusões inconclusivas...}

As colunas femininas eram o espaço em que as mulheres encontravam os conselhos necessários para conduzir uma vida feliz no lar. Simone de Beauvoir já atentava para a não existência de páginas de conselhos para a atuação masculina, dada a "naturalidade" de suas tarefas voltadas para a esfera pública. Já no domínio privado, a mulher tinha sempre que se aprimorar, posto que sua existência encontrava-se fundada na esfera privada. 
A naturalização dos papéis de feminino e masculino é reforçada por Clarice (colunista) que, por meio do veículo de comunicação pelo qual escreve, está envolta pela autoridade jornalística de formadora de opinião. A colunista assume o dever de conduzir a leitora para ensiná-la a ser mulher e feliz. A figura de uma formadora de opinião conhecedora desse determinado tipo de conhecimento e que visa iniciar também sua leitora nesse domínio é analisada por Beauvoir (1967, p. 294):

Os jornais femininos ensinam abundantemente à dona de casa a arte de conservar sua atração sexual embora lavando a louça, a permanecer elegante durante a gravidez, a conciliar o coquetismo com a maternidade e a economia; mas aquela que se sujeitasse a seguir atentamente esses conselhos logo se veria atormentada $e$ desfigurada pelas preocupações; é-lhe muito difícil permanecer desejável quando tem as mãos inchadas e o corpo deformado pelas maternidade;[...] Não é de espantar que a mulher que se debate em meio a essas contradições viva muitas vezes seus dias em estado de nervosismo e azedume; ela perde sempre, no que quer que aposte, e seus ganhos são precários, não se inscrevem em nenhum êxito seguro.

Nunca é por seu próprio trabalho que se pode salvar; esse trabalho ocupa-a, mas não constitui uma justificação: esta assenta em liberdades alheias. A mulher encerrada no lar não pode fundar ela própria sua existência; não tem os meios de se afirmar em sua singularidade e esta, por conseguinte, não lhe é reconhecida.

Os escritos clariceanos suscitam várias reflexões: Como pôde uma escritora como Clarice Lispector, tão reverenciada pela profundidade de seus temas e pelo cunho psicológico e experimental que deu a suas obras, escrever artigos tão úteis/(f)úteis, que tratam de assuntos corriqueiros e banais do universo feminino? Será que o fato de Clarice ter assinado suas "crônicas" com pseudônimos foi uma forma de encobrir sua verdadeira identidade e de rejeitar um conteúdo que procurava evitar em sua obra ficcional-artística? São suas crônicas a prova definitiva de que "a ocasião faz o ladrão"?

Conhecer essa faceta de Clarice Lispector ajuda-nos a construir o poliedro que a caracteriza por suas mil facetas. Existiu sim uma Clarice 
intelectual, introspectiva, complexa em sua multiplicidade, mas existiu também a Clarice mulher, a Clarice mãe, símbolo de seu tempo, que precisava prover seu lar com o fruto de seu trabalho e, para isso, recorreu àquilo que sabia fazer melhor: escrever. Essa Clarice precisa ser conhecida e valorizada. Quanto ao uso dos pseudônimos, é plausível afirmar que esse foi um dos tantos artifícios clariceanos. Ao assinar como uma ou outra pessoa, ela tinha a mobilidade da significação e cada uma de suas máscaras comportava uma personalidade feminina, que se revelava a cada dia, em cada dica, em cada reflexão sobre o universo das mulheres.

"Utilidade/(f)utilidade" são conceitos relativos, principalmente numa sociedade pós-moderna como a nossa, onde os extremos se chocam, se harmonizam e se complexificam. Clarice é uma digna representante das mulheres de sua e de nossa época. Suas obras, ficcionais ou não, complexas ou amenas, sugestivas ou apenas representativas, que a digam.

\section{Referências}

ARRIGUCCI, Jr, Davi. Enigma e comentário- ensaios sobre literatura e experiência. São Paulo: Cia das Letras, 1987.

BASSANEZI, Carla. Mulheres dos Anos Dourados. In: PRIORY, Mary Del. História das mulheres no Brasil. 7. ed. São Paulo: Contexto, 2004.

BUITONI, Dulcília Schroeder. Imprensa feminina. 2. ed. São Paulo: Ática, 1980.

BEAUVOIR, Simone. O segundo sexo: fatos e mitos. São Paulo: DIFEL, 1967.

CABRAL, Eugênia Melo. Primeiras Histórias O surgimentodas imprensas feminina e feminista no Brasil. BOCC. Biblioteca On-line de Ciências da Comunicação, v. 2008, p. 01-05, 2008.

GÓIS, Edma Cristina Alencar de. O dever da faceirice: o corpo e feminidade no colunismo e na ficção de Clarice Lispector. 2007. 103 f. Dissertação (Mestrado em Literatura e Práticas Sociais)-Universidade de Brasília, Brasília, 2007.

NUNES, Aparecida Maria (Org.). Correio Feminino/Clarice Lispector. Rio de Janeiro: Rocco, 2006. 
NUNES, Aparecida Maria. Uma aprendizagem ou as páginas femininas de Clarice Lispector. Revista da Anpoll, v. 1, n. 25, 2008. Disponível em: http://www.anpoll.org.br/revista/index. php/rev/article/viewFile/64/58, 2007.

ENCARTE Clarice jornalista: um ofício paralelo (sem identificação do autor) publicado como encarte da edição especial dos Cadernos de Literatura Brasileira, n. 17 e 18.

Recebido em 17 de maio de 2016.

Aceito em 18 de julho de 2016. 